Cahiers d'études africaines

\title{
PonomarenKo, Ludmila V. \& Zueva, Elena G. - L'URAP et l'Afrique
}

\section{Constantin Katsiakoris}

\section{OpenEdition}

\section{Journals}

Édition électronique

URL : http://journals.openedition.org/etudesafricaines/20782

DOI : 10.4000/etudesafricaines.20782

ISSN : 1777-5353

\section{Éditeur}

Éditions de l'EHESS

\section{Édition imprimée}

Date de publication : 1 juillet 2017

Pagination : 471-473

ISBN : 978-2-7132-2688-5

ISSN : 0008-0055

\section{Référence électronique}

Constantin Katsiakoris, " Ponomarenko, Ludmila V. \& Zueva, Elena G. - L'URAP et l'Afrique ", Cahiers d'études africaines [En ligne], 226 | 2017, mis en ligne le 01 avril 2017, consulté le 24 septembre 2020. URL : http://journals.openedition.org/etudesafricaines/20782 ; DOI : https://doi.org/10.4000/ etudesafricaines.20782

Ce document a été généré automatiquement le 24 septembre 2020.

(c) Cahiers d'Études africaines 


\title{
Ponomarenko, Ludmila V. \& ZueVA, Elena G. - L'URAP et l'Afrique
}

\author{
Constantin Katsiakoris
}

\section{RÉFÉRENCE}

Ponomarenko, Ludmila V. \& ZueVA, Elena G. - L'URAP et l'Afrique. Paris, Moscou, Éditions de l'Université de Russie de l'amitié des peuples, 2010, 136 p., http//www.rudn.ru/fr/ file.php?id=91.

1 Ce livre raconte l'histoire de l'Université de l'amitié des peuples de Russie (URAP) Rossijskij Universitet Družby Narodov (RUDN) en russe - et se concentre sur ses relations avec l'Afrique, ses étudiants et diplômés africains. Professeures d'histoire à l'URAP, Ludmila Ponomarenko et Elena Zueva ont écrit une version officielle de l'histoire de l'Université avec un ton parfois nostalgique et émotionnel. Publié en 2010 et accessible sur le site internet de l'URAP, cet ouvrage entendait commémorer les cinquante ans de la création de l'Université et rappeler sa contribution à la formation de cadres nationaux africains et au développement des relations culturelles et scientifiques entre l'Afrique, l'Union soviétique et, depuis 1991, la Fédération de Russie $^{28}$.

2 Fondée en février 1960 à Moscou, alors que les pays africains accédaient à l'indépendance, l'Université de l'amitié des peuples - alors UAP, sans la « Russie », et non pas URAP - avait été conçue comme un symbole d'internationalisme et de solidarité de l'Union soviétique avec le Tiers-monde. Ce symbolisme fut accentué l'année suivante lorsque, ainsi que le rappellent Ponomarenko et Zueva, suite à l'assassinat de Patrice Lumumba, l'Université fut rebaptisée de son nom. À partir de ce moment et jusqu'à la dissolution de l'URSS en 1991, elle fut généralement appelée Université Lumumba. Par-delà la dimension symbolique, très importante pour la politique internationale de l'URSS pendant la Guerre froide, l'Université Lumumba avait d'autres particularités. D'une part, à côté d'un nombre grandissant d'étudiants 
soviétiques, elle accueillait, en ce qui concernait les pays étrangers, exclusivement des étudiants de pays "faiblement développés " d'Asie, d'Afrique et d'Amérique latine (l'exception, ce furent quelques communistes japonais). D'autre part, elle offrait des cursus et des cours qui, du point de vue soviétique, étaient adaptés aux besoins des pays du Tiers-monde. Les critères politiques, que ce soit l'appartenance au parti communiste ou les bonnes relations entre le pays d'origine et l'URSS, jouaient un rôle décisif pour le recrutement des étudiants, alors que le marxisme-léninisme faisait partie intégrante des enseignements. C'est notamment cette identité politique et idéologique qui a été reprochée à l'Université tout au long de la Guerre froide. À l'encontre des critiques acerbes, l'Université Lumumba pouvait néanmoins se vanter du fait d'accomplir un devoir internationaliste en offrant des bourses d'études et en payant tous les frais de transport, de scolarité et de sécurité sociale pour des milliers d'étudiants qui, sans l'aide de l'URSS, n'auraient sûrement jamais pu faire d'études supérieures. Ce régime de générosité prit fin avec l'écroulement du régime soviétique.

3 Ponomarenko et Zueva passent en revue cette histoire et tentent de montrer la continuité entre l'époque soviétique et l'époque post-soviétique. Cette continuité semble être cimentée par le rôle éducatif important de l'Université et par l'amitié entre l'Afrique, l'URSS et la Russie, qui ont perduré. Leur schéma s'appuie sur un passé de grandeur et de générosité, mais dissimule la mauvaise réputation des diplômés de cette Université sur le continent africain et les effets de la grande rupture de 1989-1991, lorsque les cursus et la philosophie de l'Université ont changé et des frais de scolarité ont été introduits. Le lecteur de l'ouvrage reste ainsi avec l'impression que ce passé glorieux sert, entre autres, à construire l'image positive d'une Université qui, depuis 1989-1991, a été contrainte de se réinventer et de suivre les tendances du marché de l'éducation, bref, que le passé sert à légitimer un objectif commercial.

4 Ponomarenko et Zueva ont certes de très bonnes raisons de rappeler le passé mémorable de l'URAP. Plusieurs informations qu'elles fournissent, de manière malheureusement peu systématique, ont également leur valeur historique. Les auteures se réfèrent à des diplômés qui ont fait des carrières importantes et sont restés en relation avec l'alma mater. Elles énumèrent une série d'accords de coopération que l'Université Lumumba et ensuite l'URAP ont signés avec des universités africaines et rappellent que la période 1960-1980 était celle d'une bataille pour dissiper la méfiance contre l'Université et pour faire reconnaître son diplôme. Les pages qui relatent les activités culturelles des étudiants, par exemple les festivals internationaux ou les concours de chanson politique, donnent une idée de ce qu'était la vie culturelle officiellement organisée dans le contexte politique et idéologique de l'époque. Les pages consacrées aux vacances dans les camps de repos et de travail en Moldavie et au bord de la mer Noire, ainsi qu'aux brigades estudiantines internationales qui travaillèrent en Asie centrale et en Sibérie, sont sans doute parmi les plus intéressantes.

5 Toutefois, et c'est la grande faiblesse du livre, cette histoire officielle ne fait pas de place à tout ce qui n'était pas glorieux, voire à ce qui contredit la narration d'amitié et de solidarité. Plusieurs incidents de violence physique ou verbale, qui déclenchèrent les protestations des étudiants, ne sont pas mentionnés. Les problèmes de xénophobie et de racisme, très graves depuis la fin des années 1980, sont passés sous silence. L'événement tragique de novembre 2003, lorsque l'incendie dans une résidence de l'URAP a coûté la vie à quarante-trois étudiants d'Afrique et d'Asie, n'est même pas 
mentionné. L'histoire du mouvement étudiant syndical, qui s'est battu contre plusieurs régimes africains, est omise. De même, rien n'est pratiquement dit du mode de recrutement des étudiants communistes, ni du travail politique des hôtes soviétiques dont l'objectif était de renforcer le mouvement communiste prosoviétique contre les organisations d'opposants ou de dissidents. On regrette aussi que les auteures n'aient pas exploité les archives de l'Université pour fournir des données plus détaillées sur la répartition des étudiants, pays par pays, leurs spécialisations, les taux de réussite aux examens et leur évolution de 1960 à 2010.

6 Dans l'ensemble, le livre propose une thèse puissante sur l'importance de l'Université de l'amitié des peuples et de sa contribution au développement de l'Afrique postcoloniale, en même temps qu'il ouvre quelques pistes de réflexion et de recherche. Il doit néanmoins être lu plutôt comme un document et utilisé avec beaucoup de circonspection.

\section{NOTES}

28. L'ouvrage ne comporte pas de bibliographie. 